\title{
Retarding contaminant migration through porous media using inclined barrier walls
}

\author{
Ayman Allam ${ }^{1,2^{*}}$, Esam Helal ${ }^{3}$, Mahmoud Mansour $^{3}$ \\ ${ }^{1}$ Civil Engineering Department, Faculty of Engineering, Kafrelsheikh University, Kafrelsheikh, Egypt. \\ ${ }^{2}$ Department of Civil and Environmental Engineering, Tokyo Institute of Technology, Ookayama, Meguro-ku, Tokyo 152-8552, Japan. \\ ${ }^{3}$ Civil Engineering Department, Faculty of Engineering, Menoufia University, Menoufia, Egypt. \\ E-mails: EsamHelal@sh-eng.menofia.edu.eg, Esameman@yahoo.com (E. Helal),mahmoudmonirmansour@gmail.com (M. Mansour) \\ * Corresponding author. Tel.: +2-010-62056215. E-mails: aymanallam82@eng.kfs.edu.eg, ayman.e.aa@m.titech.ac.jp
}

\begin{abstract}
This study aims to assess the abilities of inclined barrier walls (BWs) to retard the migration of contaminants through porous media. Four cases of BW arrangements were considered, including a single inclined BW $\left(B W_{1}\right)$ and two adjacent BWs $\left(B W_{1}\right.$ and $\left.B W_{2}\right)$ with different combinations of inclination ratios (i.e., $I_{1}=\theta_{1} / 90^{\circ}$ and $\left.I_{2}=\theta_{2} / 90^{\circ}\right)$. Furthermore, the effect of the distance $(L)$ between the contamination source and $B W_{1}$ on the migration time $(T)$ was evaluated. A numerical model (GeoStudio) containing two modules (SEEP/W and CTRAN/W) was used. The model proved its reliability to simulate contaminant migration through the porous media, where the normalized objective function values between the simulated and analytical results were 0.02 and 0.04 for the discharge of seepage and concentration of contamination, respectively. The results demonstrated that the migration time was strongly influenced by the inclination ratios of the BWs. Three-dimensional regression analysis was applied to demonstrate the combined effect of the inclination ratio, $L$ and BW arrangements on $T$.
\end{abstract}

Keywords: Contaminant migration; Advection-diffusion; Inclined barrier walls; Finite element; GeoStudio.

\section{INTRODUCTION}

Water scarcity is a widespread problem in many countries around the world, particularly in arid regions (Abdelhaleem and Helal, 2015; Allam et al., 2016). Among them, Egypt faces a particularly great challenge due to its limited access to water resources (Fleifle and Allam, 2016; Sobeih et al., 2017). Moreover, the spread of pollution throughout irrigation and drainage networks threatens the sustainable agricultural use of these limited resources (El Hassan and Allam, 2017). Unfortunately, the surface water (SW) within the Egyptian irrigation and drainage networks receives a large amount of non-point source pollution. Additionally, most of the wastewater generated within Egypt is dumped into its northern lakes without treatment (El-Mezayen et al., 2018). As a widespread alternative, groundwater $(\mathrm{GW})$ represents one of the most promising and economically attractive options to enable access to additional water for different uses (El Hassan and Allam, 2017). However, solid wastes in Egypt are dumped into landfills absent any precautions for the protection of GW and/or SW resources (ElSalam and Abu-Zuid, 2015; Ibrahim and Mohamed, 2016; Ismail and Tawfik, 2015).

The dynamic behaviour of the quality of both GW and SW is commonly viewed as an impediment to the normal operation and performance of irrigation activities in Egypt (Shaban et al., 2010). Obviously, GW and SW pollution are crucial environmental problems that affect not only Egypt but also countries around the world (Barlow and Clarke, 2017). In addition, it is very difficult and expensive to restore polluted aquifers, and the costs required to monitor GW and SW pollution are very high (Strobl and Robillard, 2008). Thus, an efficient tool to protect GW and SW resources from pollution is urgently needed. In this context, the hydraulic control of contaminant migration represents one of the most common tools for the management, planning, and protection of GW and SW resources (Armanyous et al., 2016).
Controlling contaminant pollution involves either containing or redirecting contaminants along a certain direction or to a given location for a defined period. Several physical techniques have been used to control (i.e., restrict, stop, contain, or redirect) the migration of contaminants through porous fields. In this respect, the effects of vertical barrier walls (BWs) and/or extraction wells on the hydraulic control of contaminated GW have been extensively investigated by many researchers (Armanyous et al., 2016; Basha et al., 2012; Eltarabily and Negm, 2015; Guglielmetti and Butler, 1997; Nasr et al., 2003). However, despite the large number of reported studies, the process of hydraulically controlling the migration of contaminants through porous fields is still somewhat immature from an engineering perspective, as most of the abovementioned reports involved laboratory-scale experiments conducted under very limited conditions. In this context, numerical simulations constitute a simple, powerful and economical approach for predicting the migration of pollution through porous media.

Recently, several techniques have been assessed with regard to the numerical simulation of contaminant migration through porous media (Lateb et al., 2016). These methods have all proved their reliability as useful tools for evaluating the efficiency and suitability of physical techniques for controlling contaminant migration through soil (Al-Juboori and Datta, 2017; Eltarabily et al., 2015; Rathod and Sivapullaiah, 2017; Monir et al., 2018). In particular, the finite element method (FEM) represents an accurate and effective numerical technique for simulating the flow field through a porous media. Among the different types of FEM software, GeoStudio has been proven to be flexible and accurate in simulations of the flow field through porous media (Al-Juboori and Datta, 2017; GEOSLOPE International Ltd., 2017; Rathod and Sivapullaiah, 2017).

The effect of the inclination angle of BWs on the migration of contaminants through porous fields is still unclear. Therefore, the objective of this study was to investigate the retarda- 
tion of contaminant migration through porous media by using inclined BWs. More specifically, the effects of the BW inclination angle and the distance between the source of contamination and the first barrier wall on the rate of contaminant migration were investigated numerically.

\section{MATERIALS AND METHODS Numerical model}

The FEM package GeoStudio 2007 was used to simulate the spread of contaminants in porous media. The GeoStudio package includes four modules that can be employed to simulate the flow of either energy or mass (i.e., the flow modules). Accordingly, the GeoStudio model was used to simulate the effect of using inclined BWs on the retardation of contaminant migration through a porous media. Two modules were used, namely, the flow (SEEP/W) and transport (CTRAN/W) modules. The SEEP/W module is used to simulate the flow of water through saturated porous media. Additionally, the CTRAN/W module is used to simulate solute transfer by advection and diffusion, and it is coupled with SEEP/W to simulate the advection of dissolved solutes through water transfer. Detailed descriptions of the governing equations and processes included in the SEEP/W and CTRAN/W modules are presented in GEOSLPE International Ltd. (2017).

The GeoStudio model was verified in three stages. First, an analytical solution using the fragment method developed by Pavlovsky in 1935 was applied to check the results of the SEEP/W model (Griffiths, 1984). Second, an analytical solution for the one-way migration of contaminants that considers both advection and dispersion was compared with the advectiondispersion analysis of a numerical model using CTRAN/W. Finally, particle tracking analysis (PTA) was performed using a sandbox model to simulate the motion of pollutants through a porous system. A complete description of the verification process is presented in Monir et al. (2018) and Metwally et al. (2018).

The GeoStudio accuracy was evaluated using statistics based on calculations of the root mean square error (RMSE) and normalized objective function (NOF) between the simulated and analytical results as follows:

$$
\begin{aligned}
& R M S E=\sqrt{\frac{\sum_{i=1}^{N}\left(P_{\mathrm{i}}-C_{i}\right)^{2}}{N}} \\
& N O F=\frac{R M S E}{C_{\text {mean }}}
\end{aligned}
$$

where $P_{i}$ and $C_{i}$ are the predicted and analytically calculated values, respectively; $C_{\text {mean }}$ is the mean of the analytically calculated values; and $\mathrm{N}$ is the number of measurements. Model predictions are acceptable for NOF values in the interval from 0.0 to 1.0 (Allam et al., 2015).

\section{Numerical sets}

One hundred and twenty numerical runs were performed using inclined and/or vertical BWs. These runs were divided into four sets, as shown in Table 1. In Set I, a single barrier wall $\left(B W_{1}\right)$ with a varying angle of inclination $\left(\theta_{1}\right)$ was placed at a distance $(L)$ from a source of pollution. The values of $\theta_{l}$ were $45^{\circ}, 60^{\circ}, 75^{\circ}, 90^{\circ}, 105^{\circ}, 120^{\circ}$, and $135^{\circ}$, and the corresponding values of the dimensionless inclination ratio for $B W_{1}\left(I_{1}\right)$ (i.e., $\theta_{1} / 90^{\circ}$ ) were $0.50,0.67,0.83,1.0,1.17,1.33$ and 1.5 , respec- tively. In sets II, III, and IV, two BWs were used to retard the migration of contaminants, and a second $\mathrm{BW}\left(B W_{2}\right)$ was placed in succession at a constant distance $(X)$ downstream of $B W_{1}$ (Figure 1).

In Set II, $B W_{1}$ was inclined at angles of $\theta_{1}=45^{\circ}, 60^{\circ}, 75^{\circ}$, $105^{\circ}, 120^{\circ}$ and $135^{\circ}$ corresponding to $I_{1}$ values of $0.50,0.67$, $0.83,1.17,1.33$ and 1.5 , respectively, while the inclination angle of $B W_{2}\left(\theta_{2}\right)$ was kept constant at $90^{\circ}$ corresponding to a dimensionless inclination ratio $\left(I_{2}\right)$ (i.e., $\theta_{2} / 90^{\circ}$ ) of 1.0 .

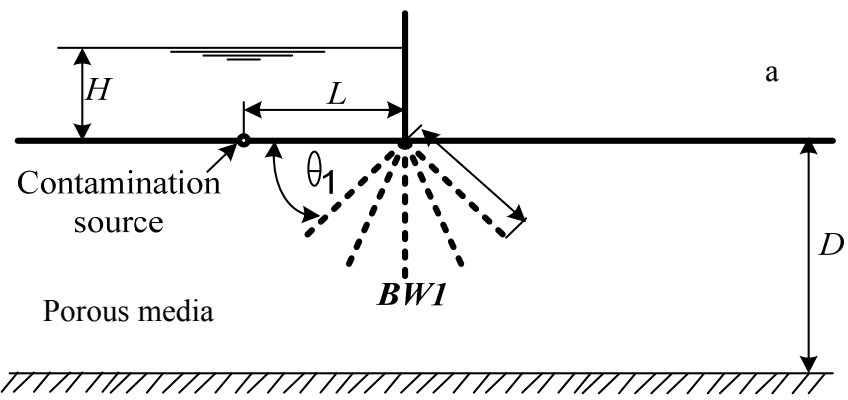

Impervious layer

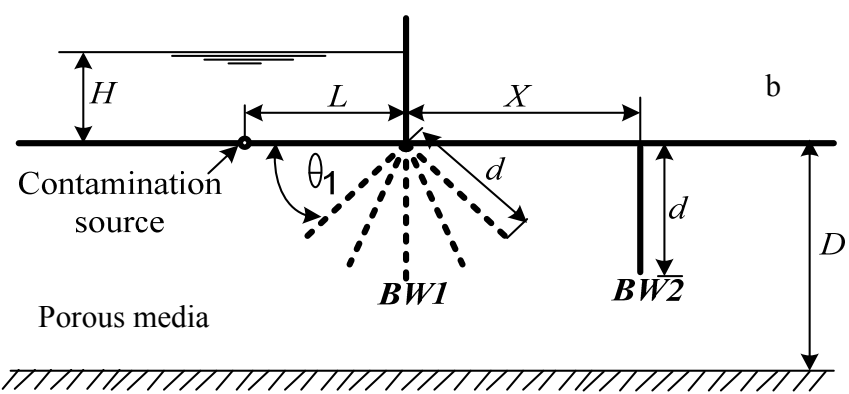

Impervious layer

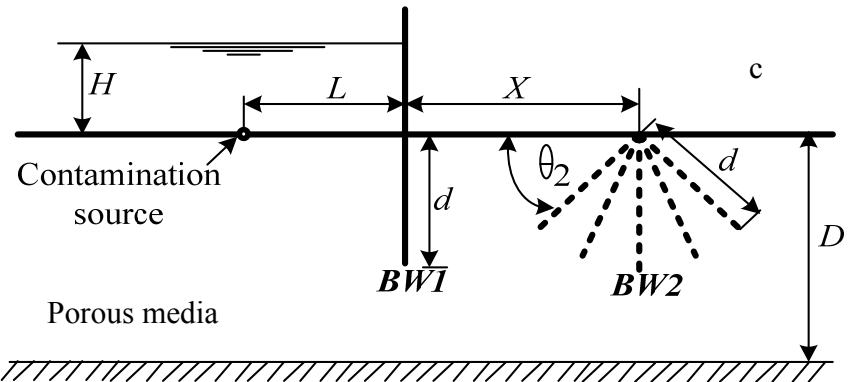

Impervious layer

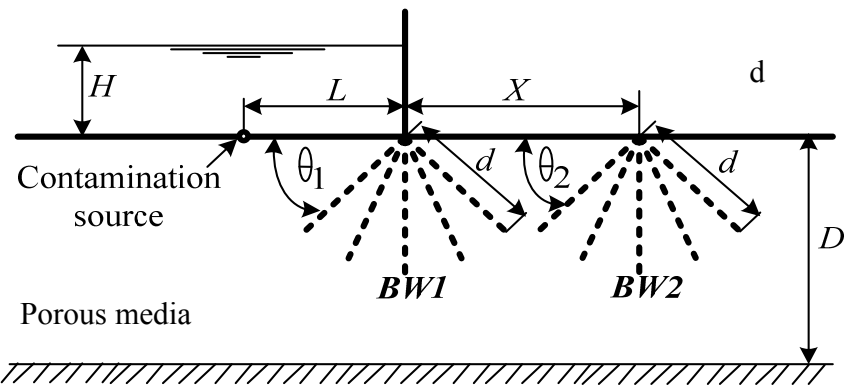

Impervious layer

Fig. 1. Barrier walls arrangements for using single inclined barrier wall $(B W)$ with different values of inclination ratio $\left(I_{1}\right)(\mathrm{a})$, case of using two $B W s$ with different values of $I_{1}$ and $I_{2}=$ one (b), $I_{1}=1.0$ and different values of $I_{2}(\mathrm{c})$, and with different values of $I_{1}$ and $I_{2}(\mathrm{~d})$. 
Table 1. Conditions of the numerical simulation sets.

\begin{tabular}{|c|c|c|c|c|c|c|c|c|}
\hline \multirow{2}{*}{$\begin{array}{l}\text { Set } \\
\text { no. }\end{array}$} & \multirow{2}{*}{ Definition } & \multirow{2}{*}{$\begin{array}{l}\text { Number } \\
\text { of Runs }\end{array}$} & \multicolumn{6}{|c|}{ Conditions } \\
\hline & & & $\theta_{1}$ & $I_{1}=\theta_{1} / 90^{\circ}$ & $\theta_{2}$ & $I_{2}=\theta_{2} / 90^{\circ}$ & $X / D$ & $L / D$ \\
\hline Set I & $\begin{array}{l}\text { Single barrier wall }\left(B W_{1}\right) \text { was } \\
\text { placed at distance }(L) \text { from a } \\
\text { source of pollution with } \\
\text { different angles of inclination } \\
\left(\theta_{1}\right)\end{array}$ & 35 & $\begin{array}{l}45^{\circ}, 60^{\circ}, 75^{\circ}, \\
90^{\circ}, 105^{\circ}, 120^{\circ} \\
\text { and } 135^{\circ}\end{array}$ & $\begin{array}{l}0.5,0.67,0.83 \\
1.0,1.17,1.33 \\
\text { and } 1.5\end{array}$ & N.A. & N.A. & N.A. & \\
\hline Set II & $\begin{array}{l}\text { The } B W_{1} \text { was used with } \\
\text { different values of } \theta_{1} \text { and } \\
\text { subsequent barrier wall } \\
\left(B W_{2}\right) \text { was placed at distance } \\
(X) \text {. The } B W_{2} \text { was vertical } \\
\left.\text { (i.e., } \theta_{2}=90\right)\end{array}$ & 30 & $\begin{array}{l}45^{\circ}, 60^{\circ}, 75^{\circ} \\
105^{\circ}, 120^{\circ} \text { and } \\
135^{\circ}\end{array}$ & $\begin{array}{l}0.5,0.67,0.83, \\
1.17,1.33 \text { and } \\
1.5\end{array}$ & $90^{\circ}$ & 1 & 0.6 & $\begin{array}{l}0.05 \\
0.10 \\
0.15 \\
0.20\end{array}$ \\
\hline Set III & $\begin{array}{l}\text { The } B W_{1} \text { was used with } \theta_{1}= \\
90^{\circ} \text { and } B W_{2} \text { was used with } \\
\text { different values of } \theta_{2}\end{array}$ & 30 & $90^{\circ}$ & 1 & $\begin{array}{l}45^{\circ}, 60^{\circ}, 75^{\circ}, 105^{\circ}, \\
120^{\circ} \text { and } 135^{\circ}\end{array}$ & $\begin{array}{l}0.5,0.67 \\
0.83,1.17 \\
1.33 \text { and } \\
1.5\end{array}$ & 0.6 & $\begin{array}{l}\text { and } \\
0.25\end{array}$ \\
\hline Set IV & $\begin{array}{l}\text { The } B W_{1} \text { and } B W_{2} \text { were used } \\
\text { with different values of } \theta_{1} \text {, } \\
\text { and } \theta_{2} \text {, respectively }\end{array}$ & 25 & $\begin{array}{l}60^{\circ} \\
60^{\circ} \\
75^{\circ} \\
75^{\circ} \\
90^{\circ}\end{array}$ & $\begin{array}{c}0.67 \\
0.67 \\
0.83 \\
0.83 \\
1\end{array}$ & $\begin{array}{l}105^{\circ} \\
120^{\circ} \\
105^{\circ} \\
120^{\circ} \\
90^{\circ}\end{array}$ & $\begin{array}{l}1.17 \\
1.33 \\
1.17 \\
1.33 \\
1\end{array}$ & & \\
\hline
\end{tabular}

N.A. indicates not applicable condition

Table 2. Soil properties for numerical model.

\begin{tabular}{ll}
\hline Properties & \multicolumn{1}{c}{ Value } \\
\hline Porosity $(n) \%$ & 0.50 \\
Hydraulic conductivity & $5 \times 10^{-6} \mathrm{~m} / \mathrm{s}$ \\
$K_{x} / K_{y}$ & 1.0 \\
Longitudinal dispersivity $\left(\alpha_{\mathrm{L}}\right)$ & $\left(0.83 \log (\mathrm{F})^{2.41}\right)^{*} 1.2 \mathrm{~m}$ (F indicates the flow path length) \\
Transverse dispersivity $\left(\alpha_{\mathrm{T}}\right)$ & $0.1 \alpha_{\mathrm{L}} \mathrm{m}$ \\
\hline
\end{tabular}

In Set III, $B W_{1}$ was inclined at $\theta_{1}=90^{\circ}$ with an $I_{1}$ value of 1.0 , while $B W_{2}$ was inclined at angles of $\theta_{2}=45^{\circ}, 60^{\circ}, 75^{\circ}, 105^{\circ}$, $120^{\circ}$ and $135^{\circ}$ corresponding to $I_{2}$ values of $0.50,0.67,0.83$, $1.17,1.33$ and 1.5 , respectively. In Set IV, $B W_{1}$ and $B W_{2}$ were used with different combinations of $\theta_{1}$ and $\theta_{2}$, as shown in Table 1; the values of $I_{1}$ were $0.67,0.83$, and 1.0 , whereas those of $I_{2}$ were $1.17,1.33$, and 1 . For all sets, two-dimensional steady-state flow was considered in a homogeneous isotropic porous media with a constant thickness $(D)$ with a hydraulic conductivity $(k)$ of $5 \times 10^{-6} \mathrm{~m} / \mathrm{s}$. Longitudinal dispersivity and transverse dispersivity was calculated according to Todd and Mays (2005). The porous media properties for the numerical model are presented in Table 2.

To evaluate the effect of the distance between the pollution source and $B W_{1}(L)$ on the contaminant migration time $(T)$, five values of $L$ were considered in the numerical simulations. The effect of $L$ was expressed in terms of the dimensionless distance ratio $(L / D)$, which took values of $0.05,0.1,0.15,0.2$, and 0.25 .

In the case of a single $\mathrm{BW}$, the time required for $5 \%$ of the initial contaminant concentration to arrive at the porous media surface downstream of the BW was determined. In the case of using two successive BWs, the time required for $5 \%$ of the initial contaminant concentration to arrive at the porous media surface downstream of $B W_{2}$ was determined. The effects of the inclination angles of the $B W s$ on the migration time of the contaminants were expressed in terms of the dimensionless time ratio $\left(T / T_{0}\right)$, where $T$ represents the migration time for $5 \%$ of the contaminant concentration to reach downstream of the BW under specific conditions, and $T_{0}$ is the migration time for $5 \%$ of the contaminant concentration to reach downstream of a vertical single BW with $L / D=0.05$.

The boundary conditions for the contaminant flow are presented in Figure 1 and Table 2. The governing equations of groundwater motion at hydrodynamic pressure liquid equilibrium, forces that resist seepage flow, gravity acceleration, and flowing acceleration forces are expressed as in Halek and Svec (1979):

$$
\left\{\begin{array}{l}
\frac{1}{m g} \frac{\partial V_{X}}{\partial t}+\frac{\partial h}{\partial x}+\frac{V_{X}}{k}=0 \\
\frac{1}{m g} \frac{\partial V_{y}}{\partial t}+\frac{\partial h}{\partial y}+\frac{V_{y}}{k}=0 \\
\frac{1}{m g} \frac{\partial V_{z}}{\partial t}+\frac{\partial h}{\partial z}+\frac{V_{z}}{k}=0
\end{array}\right.
$$

where $m$ is the mass, $g$ is gravitational acceleration, $V_{X}, V_{y}$ and $V_{z}$ are velocities components at the $x, y, z$-directions, respectively, $h$ is head, $t$ is time, and $k$ is the conductivity coefficient.

While, the equation of continuity is expressed as:

$$
\frac{\partial V_{X}}{\partial x}+\frac{\partial V_{y}}{\partial y}+\frac{\partial V_{z}}{\partial z}=0
$$

The law of conservation (advective-dispersive equation) for solute migration in saturated media was obtained (Todd and Mays, 2005):

$$
\begin{aligned}
& {\left[\left(D_{x} \frac{\partial^{2} C}{\partial x^{2}}\right)+\left(D_{y} \frac{\partial^{2} C}{\partial y^{2}}\right)+\left(D_{z} \frac{\partial^{2} C}{\partial z^{2}}\right)\right]-} \\
& {\left[\left(\bar{V}_{x} \frac{\partial c}{\partial x}\right)+\left(\bar{V}_{y} \frac{\partial c}{\partial y}\right)+\left(\bar{V}_{z} \frac{\partial c}{\partial z}\right)\right]=\frac{\partial C}{\partial t}}
\end{aligned}
$$


where $C$ is the contamination concentration and dispersion coefficients $D_{x}, D_{y}$ and $D_{z}$ do not vary through space.

\section{Regression analysis}

A three-dimensional regression analysis of the numerical results was performed to assess the impacts of the inclination ratio and the distance to the contamination source on the migration time of the contaminants for different arrangements of BWs. Using the three-dimensional plane function (Eq. 3), a statistical regression of the numerical results for $T / T_{0}$ (indicated in Eq. 3 as Z) was considered with two independent variables, namely, $L / D$ (indicated in Eq. 3 as x) and $I_{1}, I_{2}$, or $I_{1}$. $I_{2}$ (indicated in Eq. 6 as y), as follows:

$$
Z=y_{0}+a \cdot x+b \cdot y
$$

where $Z$ is the dependent variable $\left(T / T_{0}\right)$, and $a$ and $b$ are coefficients that control the plane slope. The model fitness was evaluated using analysis of variance (ANOVA), and significance ( $p$-value) was considered according to a $95 \%$ confidence level. The statistical analyses were conducted, and the surface response plots were plotted using SigmaPlot 14.0 software.

\section{RESULTS AND DISCUSSION Model verification}

The simulated seepage discharge of the contaminant calculated using the SEEP/W module and the analytical values of the seepage discharge using the fragment method are presented in Figure S1 (Supplementary). The simulation and analytical results are in good agreement. The value of the NOF was 0.02 for the seepage discharge. The SEEP/W simulations for the seepage discharge of the contaminant were satisfactory, as the value of the NOF was close to 0.0. Based on these results, the SEEP/W module can be applied to effectively simulate the migration of contaminants through porous media and around BWs.

The analytical solution of the one-way migration of contamination in consideration of both advection and dispersion was compared with the advection-dispersion analysis by using the CTRAN/W module, as shown in Figure S2. The values of the NOF were 0.015 and 0.004 for pollutant concentrations at discharge times of $T=0.315$ and 0.95 years, respectively. The CTRAN/W module verification for the simulated contaminant migration was satisfactory, as the value of the NOF was close to 0 . Based on these results, the CTRAN/W module can be applied to effectively simulate the migration of contaminants through porous media.

Furthermore, an experimental simulation of the arrival time of contaminants migrating through porous media using a sandbox model was compared with the numerical PTA in consideration of different values of $L / D$ (Figure S3), and the NOF between the experimental and numerical results of the arrival time was 0.04. Consequently, the SEEP/W and CTRAN modules can be applied to effectively simulate the migration of contaminants through porous media.

\section{The flow field of contaminants through porous media and around different arrangements of barrier walls Single inclined barrier wall}

The effects of using a single inclined barrier wall (i.e., $B W_{l}$ ) with different values of the inclination ratio $\left(I_{1}\right)$ (i.e., $I_{1}=$ $\left.\theta_{1} / 90^{\circ}\right)$ on the dimensionless ratio of the contaminant migration time $\left(T / T_{\mathrm{o}}\right)$ at different values of the dimensionless distance ratio $(L / D)$ are presented in Figure 2a. Most values of $T / T_{\mathrm{o}}$ were greater than one, which means that an inclined BW constitutes an effective mechanism for retarding contaminant migration. For $L / D=0.15,0.20$, and $0.25, T / T_{\mathrm{o}}$ exhibited an increase with an increase in $I_{1}$. For $L / D=0.05$ and $0.10, T / T_{\mathrm{o}}$ slightly increased with an increasing inclination ratio for the BW up to $I_{1}$ $=1.0$ (i.e., $\theta_{1}=90^{\circ}$ ), whereas there was no clear effect as $I_{1}$ exceeded a value of one. At $L / D=0.25$, the value of $T / T_{\mathrm{o}}$ using a single inclined BW with $I_{1}=1.5$ increased by $12 \%, 28 \%$, $33 \%, 43 \%, 49 \%$, and $54 \%$ corresponding to $I_{1}=1.33,1.17,1$, $0.83,0.67$ and 0.5 , respectively. This could be due to an increase in the flow line length of contaminants needed to reach the porous media surface downstream of the inclined BW, as described in Table S1. The results show that at $L / D=0.25$, the value of $L_{p} / D$ for $I_{1}=1.5$ increased by $7 \%, 15 \%, 17 \%, 21 \%$, $28 \%$ and $44 \%$ compared with its values at $I_{1}=1.33,1.17,1$, $0.83,0.67$ and 0.5 , respectively.
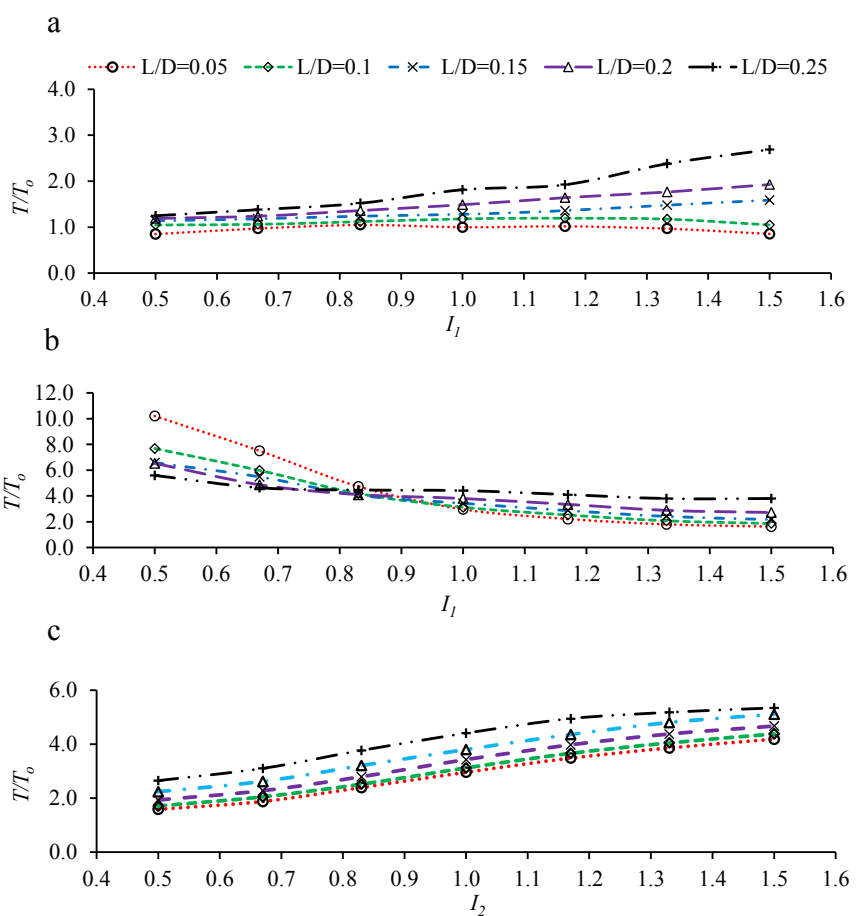

d

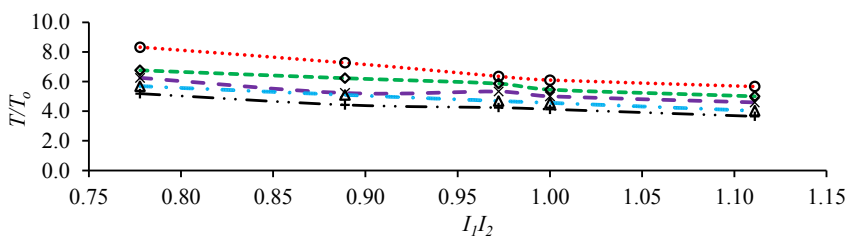

Fig. 2. The travel time dimensionless ratios at different values of $L / D$ in case of using single inclined barrier wall $(B W)$ with different values of inclination ratio $\left(I_{1}\right)(\mathrm{a})$, two $B W S$ with different values of $I_{1}$ and $I_{2}=1.0(\mathrm{~b})$, two $B W s$ with $I_{1}=1.0$ and different values of $I_{2}(\mathrm{c})$, and two $B W s$ with different values of $I_{1}$ and $I_{2}(\mathrm{~d})$.

Similarly, the $T / T_{\mathrm{o}}$ values changed as $L / D$ increased for all values of $I_{1}$. For example, the values of $T / T_{\text {o }}$ using a single inclined BW with $I_{1}=1.5$ and $L / D=0.25$ increased by $2.6 \%$, $3 \%, 3.6 \%$, and $4.3 \%$ compared with its values at $L / D=0.20$, $0.15,0.10$ and 0.05 , respectively. Hence, the effect of $I$ on $T / T_{\mathrm{o}}$ is more obvious for higher values of $\mathrm{L} / \mathrm{D}$ than for lower values. The minimum and maximum values of $T / T_{\mathrm{o}}$ were obtained at $I_{1}$ 
$=1.5$ with $L / D=0.05$ and 0.25 , respectively, which Could be due to an increase in the flow line length with increases in both the inclination angle and the distance between the barrier wall and the pollution source . In summary, the best value of $I_{1}$ for locating a single inclined $\mathrm{BW}$ to retard the downstream migration of contaminants is $I_{1}=1.5$, and the BW should be as far from the contamination source as possible. The contamination flow field through porous media using a single inclined barrier wall with $I_{1}=0.83$ at different times, the shapes of the flow lines, and the equipotential lines are presented in Figure 3. The results show that the time required for $5 \%$ of the initial contaminant concentration to arrive at the porous media surface downstream of the BW was 12.7 years with $I_{1}=0.83$ and $L / D=0.15$.
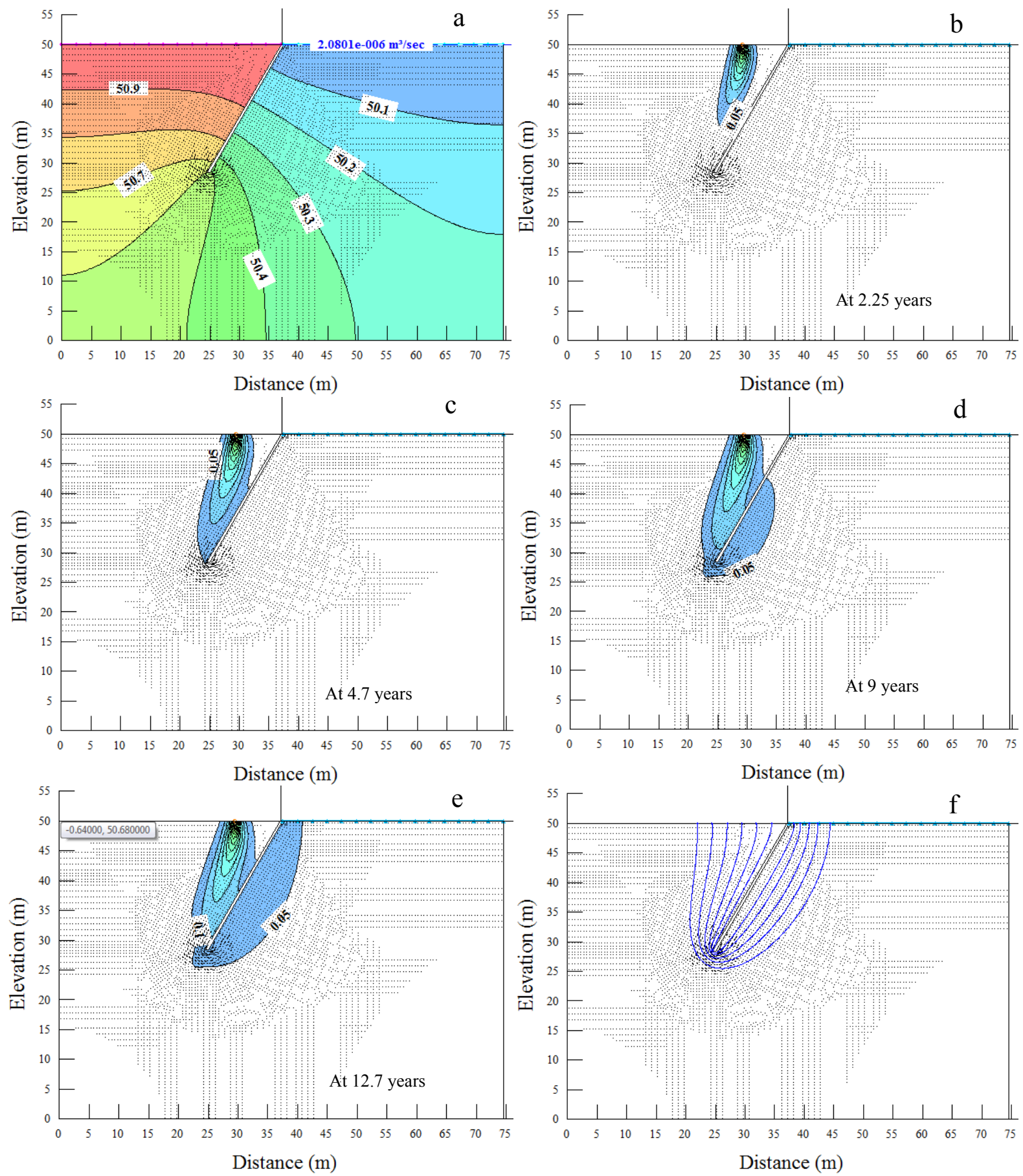

Fig. 3. Equipotential lines (a), flow filed of contaminant through soil after different times (b, c, d, e), flow lines (f) in case of using single inclined barrier wall with $I_{1}=0.83$, and $L / D=0.15$.

\section{An inclined barrier wall followed by a vertical barrier wall}

The effects of using an inclined BW with different inclination angle ratios followed by a vertical $\mathrm{BW}$ on the values of $T / T_{o}$ at different $L / D$ ratios are presented in Figure $2 \mathrm{~b}$. For all tested flow conditions, all values of $T / T_{\mathrm{o}}$ were greater than one. For all values of $L / D, T / T_{\mathrm{o}}$ decreased with an increase in $I_{1}$. For instance, the value of $T / T_{o}$ at $I_{1}=0.5$ and $L / D=0.05$ increased by $26 \%, 54 \%, 71 \%, 78 \%, 82 \%$ and $84 \%$ relative to its values at $I_{1}=0.67,0.83,1,1.17,1.33$ and 1.5 , respectively. In addition, the value of $T / T_{o}$ at $I_{1}=0.5$ and $L / D=0.25$ increased by $17 \%$, $20 \%, 21 \%, 27 \%, 32 \%$ and $39 \%$ compared with its values at $I_{1}=$ $0.67,0.83,1,1.17,1.33$ and 1.5 , respectively. These results prove that the effect of an increase in $I_{1}$ on $T / T_{\mathrm{o}}$ decreases with an increase in $L / D$, which conforms with the percolation line
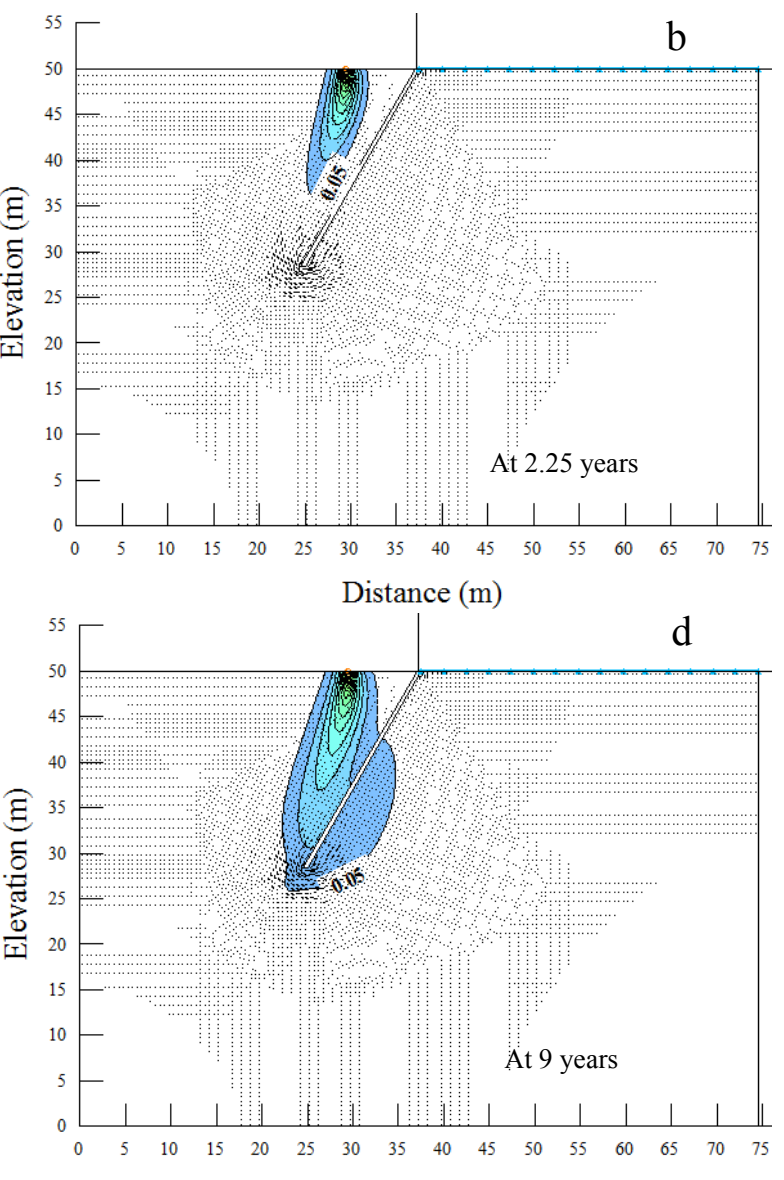
results described in Table 1S. These results show that the best arrangement for using $B W_{1}$ with different values of $\theta_{1}$ and a vertical $B W_{2}$ is the use of $B W_{1}$ with $I_{1}=0.5$ (i.e., $\theta_{1}=45^{\circ}$ ) at $L / D=0.05$. In contrast, using an inclined $\mathrm{BW}$ followed by a vertical $\mathrm{BW}$ gives higher values of $T / T_{\mathrm{o}}$ than those obtained with a single inclined BW, especially for $I_{1}<0.90$.

\section{Vertical barrier wall followed by an inclined barrier wall}

The effects of using a vertical BW followed by an inclined BW with different inclination ratios on $T / T_{0}$ at different values of $L / D$ are presented in Figure 2c. For all values of $L / D, T / T_{o}$ displayed a significant increase with an increment in $I_{2}$. At $L / D$ $=0.05$ and $I_{2}=1.5, T / T_{\mathrm{o}}$ increased by $62 \%, 55 \%, 43 \%, 29 \%$, $17 \%$ and $8 \%$ relative to its values at $I_{2}=0.5,0.67,0.83,1,1.17$, and 1.33 , respectively. In contrast, at $L / D=0.25$ and $I_{2}=1.5$, $T / T_{\mathrm{o}}$ increased by $50 \%, 42 \%, 29 \%, 17 \%, 7 \%$ and $3 \%$ compared with its values at $I_{2}=0.5,0.67,0.83,1,1.17$, and 1.33 , respectively. These results are also in accordance with the percolation line results shown in Table 1S. In summary, the best arrangement for a vertical BW followed by an inclined BW with different inclination ratios is the use of $B W_{2}$ with $I_{2}=1.5$ at $L / D=$ 0.25 . Under these circumstances, the longest flow line and the corresponding longest migration time can be attained.

Figures $2 \mathrm{~b}$ and $2 \mathrm{c}$ clarifies that the use of an inclined BW followed by a vertical $\mathrm{BW}$ gives higher values of $T / T_{\mathrm{o}}$ for $I_{1}$ values that are lower than 1.0. However, using a vertical BW
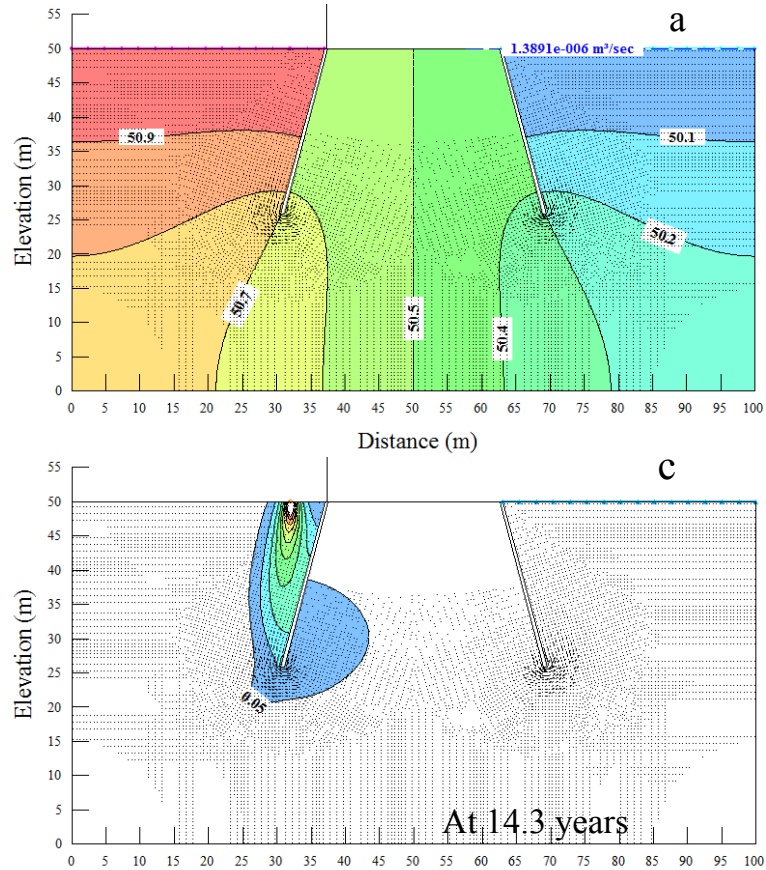

Distance (m)

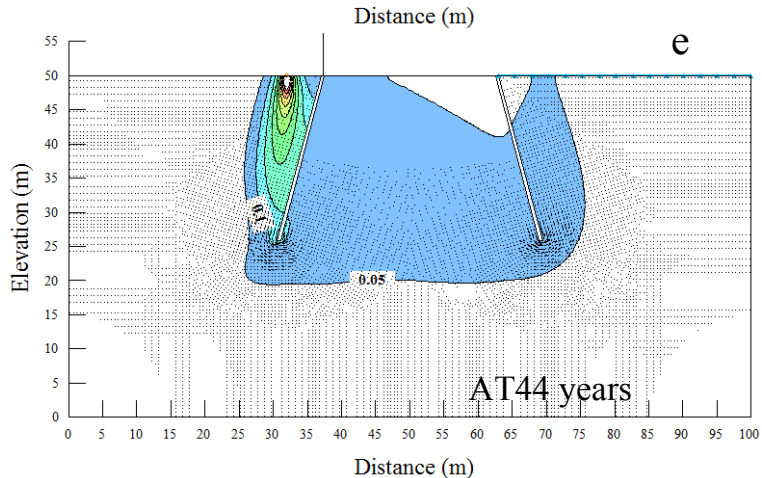

followed by an inclined BW gives higher values of $T / T_{\mathrm{o}}$ for $I_{2}$ values exceeding 1.0.

\section{Using two successive inclined barrier walls}

The effects of using two successive inclined BWs with different inclination ratios on $T / T_{\mathrm{o}}$ at different values of $L / D$ are presented in Figure 2d. The two inclination ratios (i.e., $I_{1}$ and $I_{2}$ ) were multiplied together to express the combined effect $\left(I_{1} \cdot I_{2}\right)$ of the inclination ratios of both walls on the contaminant migration time. For all values of $L / D, T / T_{\mathrm{o}}$ showed a significant decrease with an increment in $I_{1} \cdot I_{2}$. The values of $T / T_{\mathrm{o}}$ with two inclined BWs at $I_{1}=0.67$ and $I_{2}=1.17\left(I_{1} \cdot I_{2}=0.78\right)$ increased by $32 \%, 26 \%, 27 \%, 29 \%$ and $30 \%$ for $L / D=0.05,0.1,0.15,0.2$, and 0.25 , respectively, compared with its values at $I_{1}=0.83$ and $I_{2}=1.33\left(I_{1} \cdot I_{2}=1.11\right)$. In contrast, the values of $T / T_{\mathrm{o}}$ with two inclined BWs at $I_{1}=0.67$ and $I_{2}=1.33\left(I_{1} \cdot I_{2}=0.89\right)$ increased by $16 \%, 12 \%, 4 \%, 11 \%$ and $7 \%$ for $L / D=0.05,0.1,0.15,0.2$, and 0.25 , respectively, compared with its values at $I_{1}=1.0$ and $I_{2}=1.0\left(I_{1} \cdot I_{2}=1.0\right)$. These results show that the effects of $I_{I}$ and $I_{2}$ on $T / T_{\mathrm{o}}$ decrease with an increase in the value of $L / D$. In summary, the use of two successive inclined BWs gives higher values of $T / T_{0}$, especially for higher values of $I_{1}$ and $I_{2}$. The flow field of contamination through porous media with two successive inclined BWs at $I_{1}=0.83$ and $I_{2}=1.16$ at different times, the shapes of the flow lines, and the equipotential lines are all presented in Figure 4.

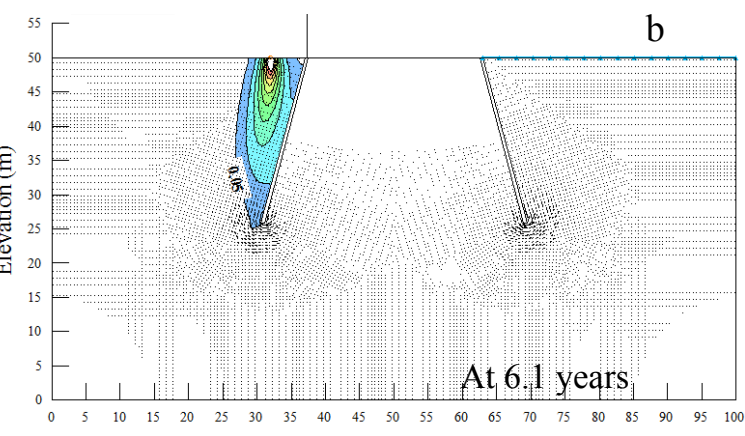

Distance $(\mathrm{m})$
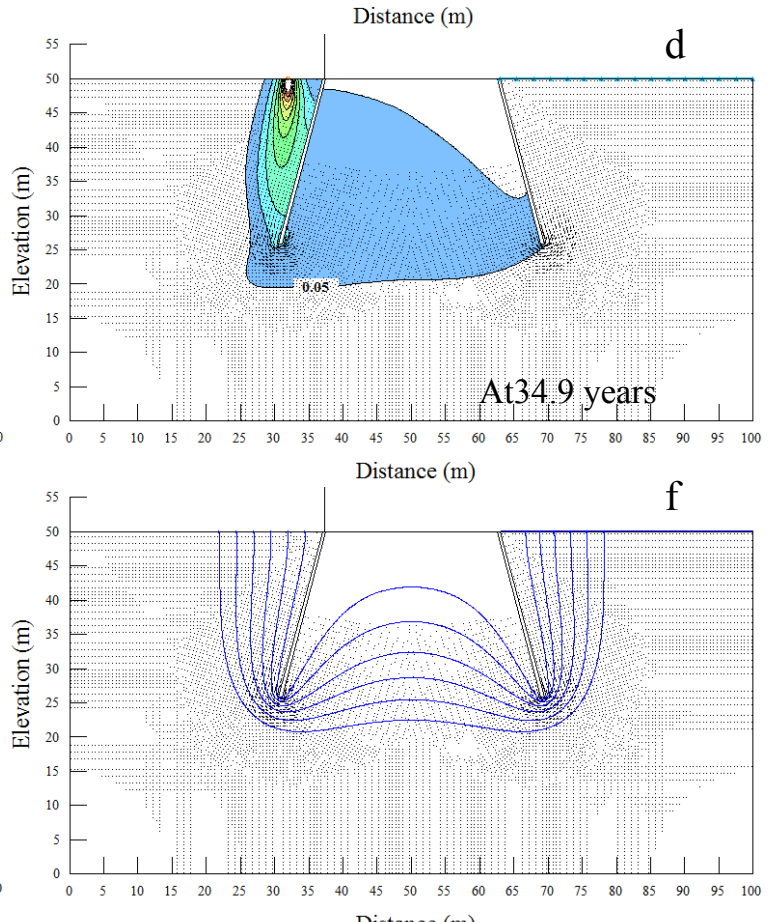

Distance $(\mathrm{m})$

Fig. 4. Equipotential lines (a), flow filed of contaminant through soil after different times (b, c, d, e), flow lines (f) in case of using two inclined barrier walls with $I_{1}=0.83, I_{2}=1.16$ and $L / D=0.1$. 
Comparison between different barrier wall arrangements

A comparison among different barrier arrangements, namely, the single vertical barrier arrangement examined by Basha et al. (2012), the two equal barriers with solid floors evaluated by Metwally et al. (2018), and the arrangements examined in the present study (Set I, Set II, Set III, and Set IV), is presented in Figure 5. This comparison shows that the value of $T / T_{0}$ with a single inclined BW increases relative to its value with the single vertical barrier of Basha et al. (2012) by a value ranging from $19.5 \%$ to $32.5 \%$. In contrast, the values of $T / T_{0}$ with the inclined BWs in Set II, Set III, and Set IV increased by values ranging from $27 \%$ to $244 \%$, from $21 \%$ to $41 \%$, and from $18 \%$ to $181 \%$, respectively, relative to the corresponding values for two equal barriers with solid floors as suggested by Metwally et al. (2018). Furthermore, the values of $T / T_{0}$ for Set II, Set IV and Set III increased compared with its values for the single vertical barrier of Basha et al. (2012) by values ranging from $209 \%$ to $920 \%$, from $194 \%$ to $318 \%$, and from $185 \%$ to $732 \%$, respectively. These results prove the effectiveness of using inclined $\mathrm{BW}$ as opposed to vertical $\mathrm{BW}$ for retarding the migration of contaminants.

\section{Three-dimensional regression analysis of the contaminant migration time}

The three-dimensional plane equation (Eq. 6) was applied for the three-dimensional regression analysis of the numerical results. The combined effect of $L / D(\mathrm{x})$ with $I_{1}, I_{2}$, or $I_{1} \cdot I_{2}(\mathrm{y})$ on the migration time $\left(T / T_{0}\right)$ was extensively assessed. Accordingly, the following equations were obtained as functions of the inde- endent variables ( $\mathrm{x}$ and $\mathrm{y}$ ) to fit the observed data (Eqs. 7-10):

$$
\begin{aligned}
& \frac{T}{T_{0}}=0.246+3.711(x)+0.511(y) \\
& \frac{T}{T_{0}}=7.692+1.512(x)-3.848(y) \\
& \frac{T}{T_{0}}=-0.402+6.501(x)+2.879(y) \\
& \frac{T}{T_{0}}=12.481-11.764(x)-5.591(y)
\end{aligned}
$$

where Eqs. (7), (8), (9), and (10) represent $T / T_{0}$ for a single $\mathrm{BW}$, two BWs where $B W_{1}$ is inclined, two BWs where $B W_{2}$ is inclined, and two inclined BWs, respectively. The predicted values of $T / T_{0}$ were statistically compared with the simulated values using ANOVA, as shown in Table 3.

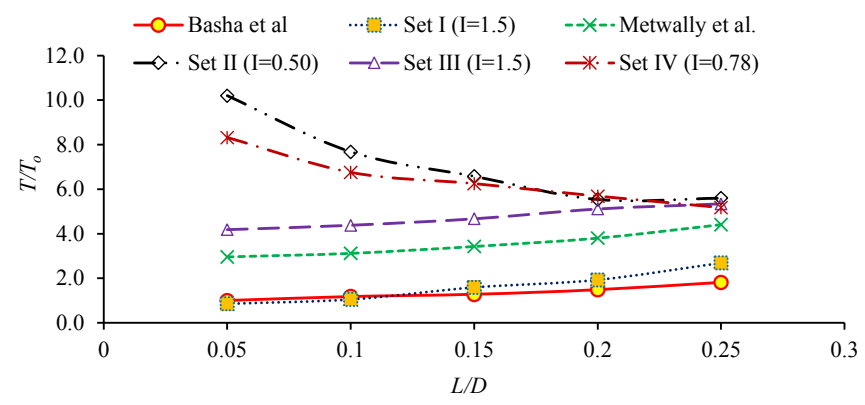

\begin{tabular}{|c|c|c|c|c|c|c|}
\hline \multirow[t]{10}{*}{ Single BW } & & Degree of freedom & Sum of squares & Mean square & F-value & P-value \\
\hline & Regression & 3 & 63.7509 & 21.2503 & 36.7157 & $<0.0001$ \\
\hline & Residual & & 1.4901 & 0.0466 & & \\
\hline & Total & 35 & 65.241 & 1.864 & & \\
\hline & $\mathrm{R}$ & $\mathrm{R}^{2}$ & Adjusted $\mathrm{R}^{2}$ & Standard erro & imate & \\
\hline & 0.8346 & 0.6965 & 0.6775 & 0.2158 & & \\
\hline & & Coefficient & Standard error & t-value & & \\
\hline & $\mathrm{y}_{0}$ & 0.2459 & 0.1389 & 1.7706 & 0.0862 & \\
\hline & $\mathrm{a}$ & 3.706 & 0.5158 & 7.1845 & $<0.0001$ & \\
\hline & $\mathrm{b}$ & 0.5111 & 0.1094 & 4.6706 & $<0.0001$ & \\
\hline \multirow[t]{10}{*}{ Two BW and the 1 st one is inclined } & & Degree of freedom & Sum of squares & Mean square & F-value & P-value \\
\hline & Regression & 3 & 637.9384 & 212.6461 & 97.6634 & $<0.0001$ \\
\hline & Residual & 32 & 9.4998 & 0.2969 & & \\
\hline & Total & 35 & 647.4382 & 18.4982 & & \\
\hline & $\mathrm{R}$ & $\mathrm{R}^{2}$ & Adjusted $\mathrm{R}^{2}$ & Standard erro & imate & \\
\hline & 0.9269 & 0.8592 & 0.8504 & 0.5449 & & \\
\hline & & Coefficient & Standard error & $\mathrm{t}$-value & P-value & \\
\hline & $\mathrm{y}_{0}$ & 7.6919 & 0.3507 & 21.9331 & $<0.0001$ & \\
\hline & $\mathrm{a}$ & 1.5125 & 1.3025 & 1.1613 & 0.2541 & \\
\hline & $\mathrm{b}$ & -3.8481 & 0.2763 & -13.9276 & $<0.0001$ & \\
\hline \multirow[t]{10}{*}{ Two BW and the 2nd one is inclined } & & Degree of freedom & Sum of squares & Mean square & & \\
\hline & Regression & 3 & 456.6856 & 152.2285 & & \\
\hline & Residual & 32 & 0.7331 & 0.0229 & & \\
\hline & Total & 35 & 457.4187 & 13.0691 & & \\
\hline & $\mathrm{R}$ & $\mathrm{R}^{2}$ & Adjusted $\mathrm{R}^{2}$ & Standard erro & imate & \\
\hline & 0.9909 & 0.9818 & 0.9807 & 0.1514 & & \\
\hline & & Coefficient & Standard error & t-value & P-value & \\
\hline & $\mathrm{y}_{0}$ & -0.4021 & 0.0975 & -4.124 & 0.0002 & \\
\hline & $\mathrm{a}$ & 6.5 & 0.3618 & 17.9654 & $<0.0001$ & \\
\hline & $\mathrm{b}$ & 2.8794 & 0.0769 & 37.4637 & $<0.0001$ & \\
\hline \multirow[t]{10}{*}{ Two BW and both are rotating } & & Degree of freedom & Sum of squares & Mean square & & \\
\hline & Regression & 3 & 757.3452 & 252.4484 & & \\
\hline & Residual & 22 & 1.3968 & 0.0635 & & \\
\hline & Total & 25 & 758.742 & 30.3497 & & \\
\hline & $\mathrm{R}$ & $\mathrm{R}^{2}$ & Adjusted $\mathrm{R}^{2}$ & Standard erro & imate & \\
\hline & 0.9749 & 0.9505 & 0.946 & 0.252 & & \\
\hline & & Coefficient & Standard error & t-value & P-value & \\
\hline & $\mathrm{y}_{0}$ & 12.4815 & 0.4493 & 27.7821 & $<0.0001$ & \\
\hline & $\mathrm{a}$ & -11.764 & 0.7127 & -16.5065 & $<0.0001$ & \\
\hline & $\mathrm{b}$ & -5.5908 & 0.4563 & -12.2538 & $<0.0001$ & \\
\hline
\end{tabular}

Fig. 5. Comparison between different barriers arrangements (I indicates the inclination ratio of barrier wall).

Table 3. Statistical analysis of ANOVA and 3D regression (plane) coefficients. 
a
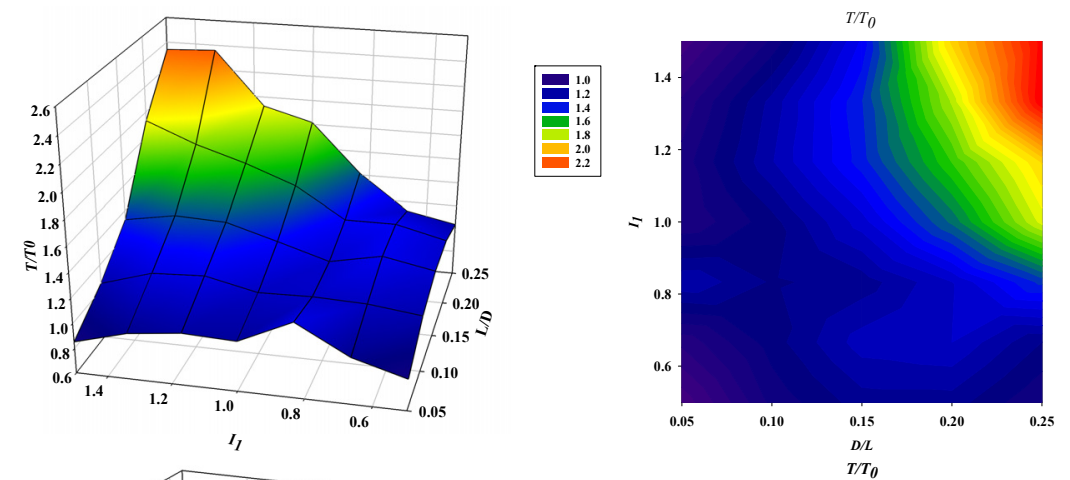

b
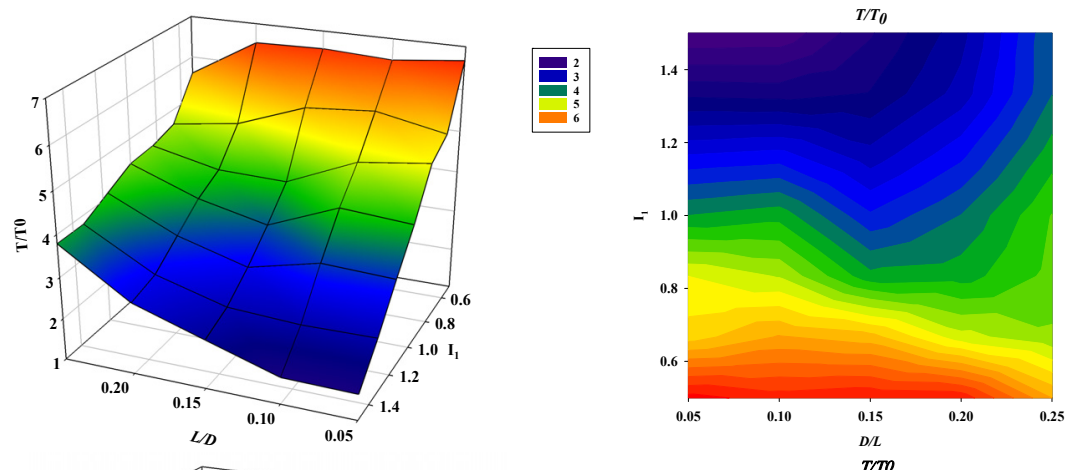

$\mathrm{c}$
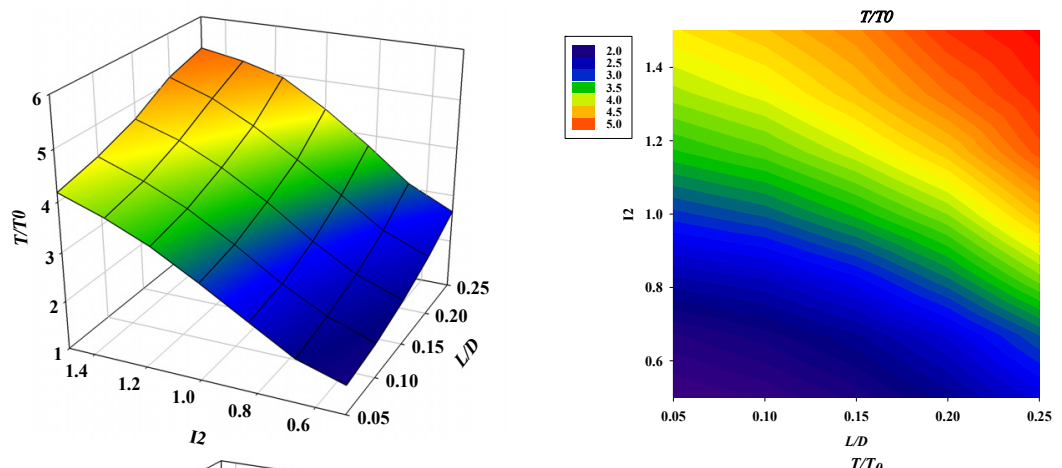

$\mathrm{d}$
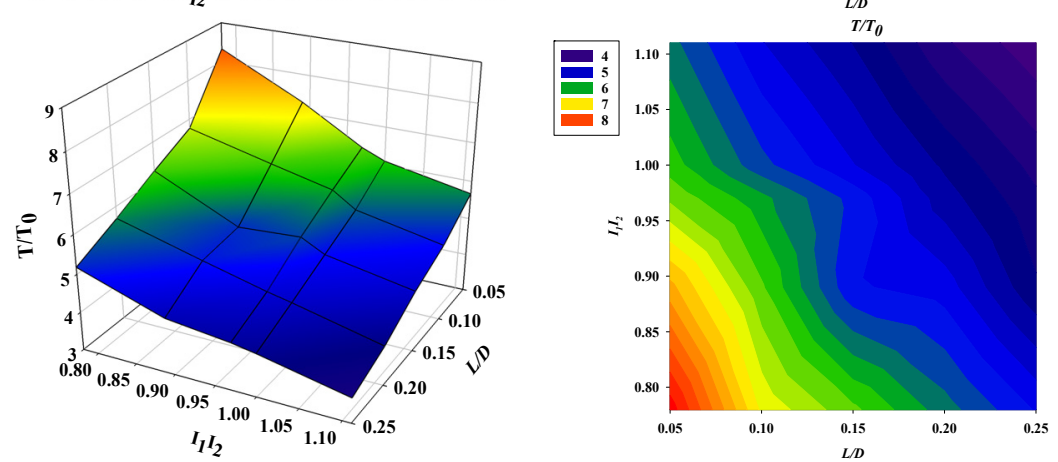

Fig. 6. Three-dimensional and contour plots of the representing the combination of $L / D$ and $I_{1}$, or $I_{2}$, or $I_{1} \cdot I_{2}$ and the resulted transport time $\left(T / T_{0}\right)$ for single inclined barrier wall (a), two barrier walls and the $1^{\text {st }}$ one is inclined (b), two barrier walls and the $2^{\text {nd }}$ one is inclined (c), and using two inclined barrier walls (d).

The results reveal that the $R^{2}$ values of the four models statistically fitted to the simulated data ranged from 0.69 to 0.98 . The F-values were higher than the p-values (low probability), indicating that the predicted results are significant. The threedimensional plots for $T / T_{0}$ as functions of $L / D$ and $I_{1}, I_{2}$, or $I_{1} . I_{2}$ are also shown in Figure 6. In this analysis, a peak value for $T / T_{0}$ was clearly detected; therefore, the maximum $T / T_{0}$ value can be recorded under the conditions used herein.

\section{CONCLUSIONS}

The effects of using inclined barrier walls (BWs) on the contaminant migration time $\left(T / T_{\mathrm{o}}\right)$ through porous media was eval- uated. A numerical model (GeoStudio) with two modules (SEEP/W and CTRAN/W) was used to simulate groundwater (GW) flow and solute migration through porous media. Four cases of BW arrangements were considered, including a single $\mathrm{BW}\left(B W_{1}\right)$ and two successive BWs $\left(B W_{1}\right.$ and $\left.B W_{2}\right)$ with different combinations of inclination angles (i.e., $\theta_{1}$ and $\theta_{2}$ for $B W_{1}$ and $B W_{2}$, respectively). The model accuracy was evaluated using statistics based on calculations of the normalized objective function (NOF) between the simulated and analytical results. The values of the NOF were 0.02 and 0.04 for the discharge of seepage and concentration of contamination, respectively. Accordingly, the model proved its reliability to simulate contaminant migration through porous media, as the NOF val- 
ues were close to zero. For a single BW, $T / T_{\mathrm{o}}$ increased with an increase in $I_{1}$. Moreover, the effect of an increase in $I_{1}$ on $T / T_{0}$ decreased with an increase in $L / D$. The best $I_{1}$ value for a single inclined $\mathrm{BW}$ to retard the downstream migration of contaminants is $I_{1}=1.5$, and the BW should be located as far from the contamination source as possible.

In the case with an inclined BW followed by a vertical BW, for all values of $L / D, T / T_{\mathrm{o}}$ decreased with an increase in $I_{1}$. Additionally, the effect of an increase in $I_{1}$ on $T / T_{\mathrm{o}}$ decreased with an increase in $L / D$. In the case with a vertical BW followed by an inclined $\mathrm{BW}$, for all values of $L / D, T / T_{\mathrm{o}}$ significantly increased with an increment in $I_{2}$; for all values of $L / D$, $T / T_{\mathrm{o}}$ significantly decreased with an increment in $I_{1} \cdot I_{2}$. Moreover, the effects of the inclination ratios $I_{1}$ and $I_{2}$ on $T / T_{\mathrm{o}}$ decreased with an increase in $L / D$. In summary, the migration time was strongly influenced by the inclination angles of the BWs; for all tested conditions, $T / T_{o}>1$, indicating that inclined BWs have a significant ability to retard contaminant migration. Three-dimensional regression analysis was applied to examine the combined effect of the BW inclination angles, the distance to the source of contamination and the arrangements of BWs on the contaminant migration time. These three-dimensional models could be effectively used to quantify the effects of inclined BW on the hydraulic retardation of contaminant flow fields through porous media.

Acknowledgements. The authors would like to thank the staff of the Irrigation and Hydraulics Laboratory, Civil Engineering Department, Faculty of Engineering, Menoufia University, Egypt, for their valuable support during the experimental work of this study.

\section{REFERENCES}

Abdelhaleem, F.S., Helal, E.Y., 2015. Impacts of Grand Ethiopian Renaissance Dam on different water usages in upper Egypt. Br. J. Appl. Sci. Technol., 8, 5, 461-483.

Al-Juboori, M., Datta, B., 2017. Influence of hydraulic conductivity and its anisotropy ratio on the optimum hydraulic design of water retaining structures founded on permeable soils. In: $13^{\text {th }}$ Hydraulics in Water Engineering Conference (p. 220). Engineers Australia.

Allam, A., Tawfik, A., Yoshimura, C., Fleifle, A., 2016. Multiobjective models of waste load allocation toward a sustainable reuse of drainage water in irrigation. Environ. Sci. Pollut. Res., 23, $12,11823-11834$.

Allam, A., Fleifle, A., Tawfik, A., Yoshimura, C., El-Saadi, A., 2015. A simulation-based suitability index of the quality and quantity of agricultural drainage water for reuse in irrigation. Sci. Total Environ., 536, 79-90.

Armanyous, A.M., Ghoraba, S.M., Rashwan, I.M.H., Dapaon, M.A., 2016. A study on control of contaminant transport through the soil using equal double sheet piles. Ain Shams Eng. J., 7, 1, 21-29.

Basha, A.M.A, Al Nimr, A., Rashwan, I.M.H., Gabr, A.M., 2012. Use of sheet piles to control contaminant transport through the soil. J. Am. Sci., 8, 12, 568-573. (ISSN: 1545-1003). http://www.jofamericanscience.org.

Barlow, M., Clarke, T., 2017. Blue Gold: The Battle against Corporate Theft of the World's Water. The New Press, Routledge.

El Hassan, W., Allam, A., 2017. Management of the integration between irrigation and drainage water in the Nile Delta. In: Barceló, D., Kostianoy, A.G. (Eds.): The Handbook of Environmental Chemistry. Springer, Berlin, Heidelberg, pp. 1-8.

Eltarabily, M.G.A., Negm, A.M., 2015. Numerical simulation of fertilizers movement in sand and controlling transport process via vertical barriers. Int. J. Environ. Sci. Dev., 6, 8, 559-568.

Eltarabily, M., Negm, A.M., Valeriano, O.C.S., 2015. Protection of irrigation water from phosphate transport through the layered soil by using vertical barriers walls. In: Eighteenth International Water Technology Conference, IWTC18, Sharm ElSheikh, pp. 12-14.
El-Salam, M.M.A., Abu-Zuid, G.I., 2015. Impact of landfill leachate on the groundwater quality: A case study in Egypt. J. Adv. Res., 6, 4, 579-586.

El-Mezayen, M.M., Rueda-Roa, D.T., Essa, M.A., Muller-Karger, F.E., Elghobashy, A.E., 2018. Water quality observations in the marine aquaculture complex of the Deeba Triangle, Lake Manzala, Egyptian Mediterranean coast. Environ. Monit. Assess., 190, 7, 436-445.

Fleifle, A., Allam, A., 2016. Remediation of Agricultural Drainage Water for Sustainable Reuse. In: The Nile Delta. Springer, Cham, pp. 297-324.

GEOSLOPE International Ltd., 2017. Heat and Mass Transfer Modeling with GeoStudio 2018. 2nd Ed. Calgary, Alberta, Canada.

Griffiths, D.V., 1984. Rationalized charts for the method of fragments applied to confined seepage. Géotechnique, 34, 2, 229-238.

Guglielmetti, J.L., Butler, P.B., 1997. Use of a geomembrane steel sheet pile verticle barrier to curtail organic seepage. No. CONF970208--PROC.

Halek, V., Svec, J., 1979. Groundwater Hydraulics. Elsevier Scientific Publishing Company, New York, pp. 19-50.

Ibrahim, M.I.M., Mohamed, N.A.E.M., 2016. Towards sustainable management of solid waste in Egypt. Procedia Environ. Sci., 34, 336-347.

Ismail, S., Tawfik, A., 2015. Treatment of hazardous landfill leachate using Fenton process followed by a combined (UASB/DHS) system. Water Sci. Technol., 1700-1708.

Lateb, M., Meroney, R.N., Yataghene, M., Fellouah, H., Saleh, F., Boufadel, M.C., 2016. On the use of numerical modelling for nearfield pollutant dispersion in urban environments - A review. Environ. Pollut., 208, 271-283.

Metwally, N., Sobieh, M., Rashwan I., Helal, E., 2018. Control of contaminant transport using equal double sheet piles with impervious floor. M.Sc. Thesis. Civil Engineering Department, Menoufia University, Egypt.

Monir, M.M., Ellayn, F., Rashwan, I., Sobieh, M., Helal, E., 2018. Delaying solute transport through the soil using unequal double sheet piles with a surface floor. Ain Shams Engineering Journal, 9, 4, 3399-3409.

Nasr, R., Zeydan, B., Ghoraba, S.M., 2003. Three-dimensional finite element analysis of seepage around heading up structures. Mansoura Eng. J., 28, 1, 68-92.

Rathod, D., Sivapullaiah, P.V., 2017. Migration of Sulphate Under Different Conditions: Electro-Kinetic Remediation Technique. Indian Geotechnical Journal, 47, 4, 485-494.

Shaban, M., Urban, B., El Saadi, A., Faisal, M., 2010. Detection and mapping of water pollution variation in the Nile Delta using multivariate clustering and GIS techniques. J. Environ. Eng., 91, 1785-1793.

Sobeih, M.M., Arabi, N.E., Helal, E., Awad, B.S., 2017. Management of water resources to control groundwater levels in the southern area of the western Nile delta, Egypt. Water Science, 31, 2, 137-150.

Strobl, R.O., Robillard, P.D., 2008. Network design for water quality monitoring of surface freshwaters: A review. J. Environ. Manage., $87,4,639-648$.

Todd, D.K., Mays, L.W., 2005. Groundwater Hydrology. 3rd Ed. Wiley.

Received 3 December 2018 Accepted 19 March 2019

\section{NOMENCLATURE}

$B W_{1} \quad$ First barrier wall

$B W_{2} \quad$ Second barrier wall

C Contaminant concentration

$\mathrm{C}_{\mathrm{s}} \quad$ Contaminant concentration at source

$d \quad$ Depth of barrier walls

$D \quad$ Soil layer thickness (i.e., effective depth of aquifer in meters)

$H \quad$ Head difference between upstream and down- $\quad$ L stream $(\mathrm{m})$

$k$ Hydraulic conductivity $(\mathrm{m} / \mathrm{s}) \quad \mathrm{L}^{-1} \mathrm{~T}^{-1}$

-
-
$\mathrm{ML}^{-3}$
$\mathrm{ML}^{-3}$
$\mathrm{~L}$
$\mathrm{~L}$
$\mathrm{~L}$
$\mathrm{~L}^{-1} \mathrm{~T}^{-}$


$L \quad$ Distance between the contamination source and the $1^{\text {st }}$ barrier wall $(\mathrm{m})$

$L_{p} \quad$ Flow path length (m)

$Q \quad$ Seepage discharge $\left(\mathrm{m}^{3} / \mathrm{s}\right)$

$\underset{T}{Q} \quad$ Arrival time of $5 \%$ of the contaminant concen- $\quad \mathrm{L}^{3} \mathrm{~T}$ tration downstream

$T_{o} \quad$ Arrival time of 5\% of the contaminant concen- $\quad \mathrm{T}$ tration using a single vertical barrier wall downstream for $L / D=0.05$ and $I_{1}=1$

$X \quad$ Distance between two adjacent barrier walls in meters (i.e., the length of the solid floor between the barrier walls)

i Dimensional form factor in the $i^{\text {th }}$ fragment

$\theta_{1} \quad$ Inclination angle of the first barrier wall with the horizontal direction upstream

$\theta_{2} \quad$ Inclination angle of the second barrier wall with the horizontal direction upstream

\section{SUPLEMENTARY}

Table S1. Flow path lengths for different barrier wall arrangements.

\begin{tabular}{lccccccc}
\hline & & \multicolumn{6}{c}{ Flow path length $(\mathrm{m})$} \\
\cline { 2 - 8 } Set No. & \multirow{2}{*}{$I_{1}$} & $I_{2}$ & $L / D=$ & $L / D=$ & $L / D=$ & $L / D=$ & $L / D=$ \\
& & 0.05 & 0.10 & 0.15 & 0.20 & 0.25 \\
\hline \multirow{6}{*}{ Set I } & 0.50 & & 47.3 & 47.3 & 47.4 & 47.5 & 48.8 \\
& 0.67 & & 51.0 & 52.4 & 55.0 & 58.6 & 62.9 \\
& 0.83 & & 52.1 & 54.9 & 58.6 & 63.2 & 68.4 \\
& 1.00 & N.A. & 52.6 & 56.4 & 61.1 & 66.4 & 72.2 \\
& 1.17 & & 51.9 & 56.7 & 62.1 & 67.9 & 74.1 \\
& 1.33 & & 51.9 & 56.7 & 62.1 & 67.9 & 74.1 \\
& 1.5 & & 49.8 & 55.3 & 61.3 & 67.6 & 73.9 \\
\hline \multirow{4}{*}{ Set II } & 0.50 & & 116.0 & 108.0 & 103.0 & 98.9 & 95.9 \\
& 0.67 & & 105.0 & 101.4 & 95.7 & 93.8 & 94.6 \\
& 0.83 & 1.00 & 97.0 & 91.3 & 89.6 & 91.2 & 94.9 \\
& 1.17 & & 76.1 & 78.7 & 83.8 & 89.8 & 96.2 \\
& 1.33 & & 70.3 & 76.3 & 83.0 & 89.8 & 96.7 \\
& 1.50 & & 68.6 & 75.7 & 82.9 & 90.0 & 97.1 \\
\hline \multirow{5}{*}{ Set III } & & 0.5 & 63.9 & 67.1 & 71.7 & 77.2 & 83.4 \\
& & 0.67 & 68.5 & 70.6 & 75.2 & 80.8 & 87.0 \\
& 1.00 & 0.83 & 76.6 & 76.8 & 80.3 & 85.4 & 91.3 \\
& & 1.17 & 92.8 & 89.6 & 90.8 & 94.4 & 99.3 \\
& & 1.33 & 97.4 & 93.7 & 94.2 & 97.3 & 101.8 \\
& & 1.5 & 99.1 & 95.5 & 95.8 & 98.5 & 102.7 \\
\hline \multirow{6}{*}{ Set IV } & 0.67 & 1.17 & 106.8 & 101.4 & 98.8 & 99.3 & 101.9 \\
& 0.83 & 1.17 & 103.3 & 97.4 & 95.1 & 96.1 & 99.1 \\
& 0.67 & 1.33 & 111.0 & 109.3 & 104.5 & 102.1 & 102.2 \\
& 0.83 & 1.33 & 113.5 & 106.6 & 101.3 & 98.9 & 99.3 \\
& 1.00 & 1 & 85.5 & 83.5 & 85.8 & 90.1 & 95.6 \\
\hline
\end{tabular}

$\mathrm{L}$
L

$\mathrm{L}$

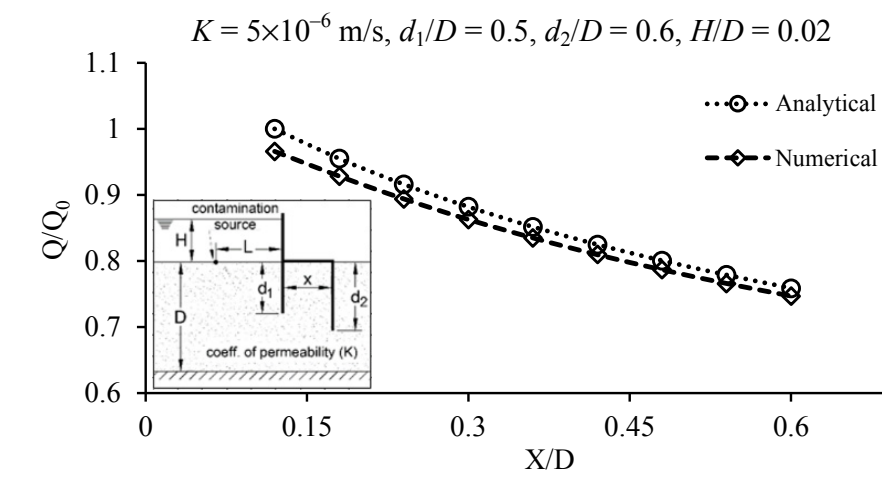

Fig. S1. The seepage discharge of contaminant by using fragments method (analytical) and SEEP/W model (numerical) at different values of X/D after Monir et al. (2018).

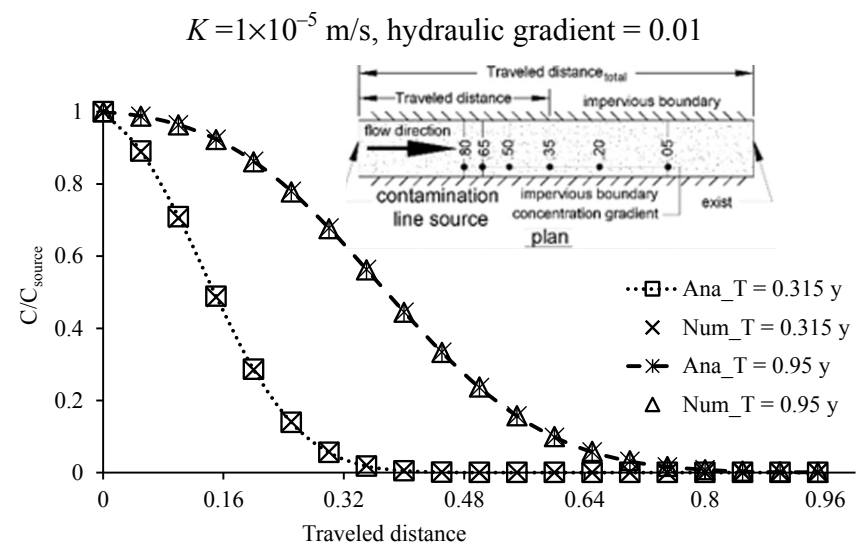

Fig. S2. The distance from the contamination source and contamination concentration for analytical and numerical solutions at two different periods after Monir et al. (2018).

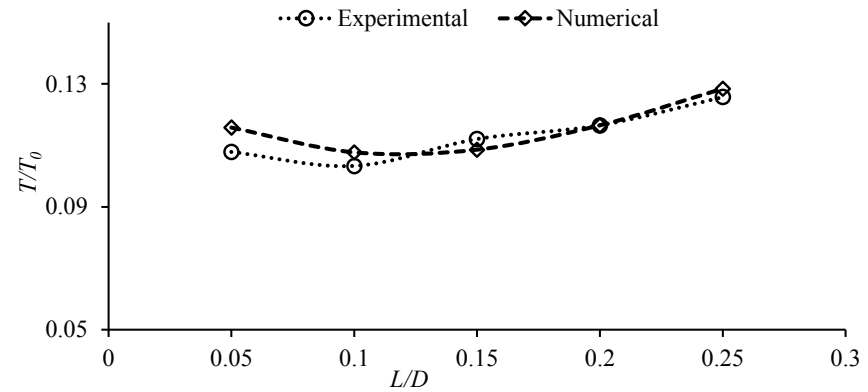

Fig. S3. The arrival time of contaminant by using experimental and numerical particle tracking analysis after Monir et al. (2018). 